\title{
Spatial and Temporal Variability in Tidal Range: Evidence, Causes, and Effects
}

\author{
David F. Hill ${ }^{1}$
}

Published online: 28 July 2016

(C) Springer International Publishing AG 2016

\begin{abstract}
Tidal range is one factor in determining the vertical location of local mean sea level, and it is also a contributor to total water levels and coastal flooding. It is therefore important to understand both the spatial distribution of tidal range and the temporal variation in tidal range, over a wide range of scales. Knowledge of historic tidal range is obtained both through observations and through modeling. This paper reviews numerous observational and modeling studies of historic tidal range variations on decadal to millennial timescales. It also discusses many of the physical processes that are responsible for these variations. Finally, this paper concludes with discussion of several modeling studies that seek to constrain future changes in tidal range in coastal environments.
\end{abstract}

Keywords Tidal range $\cdot$ Tidal modeling $\cdot$ Tide gauges $\cdot$ Sea level change $\cdot$ Tidal dissipation

\section{Introduction}

Coastal water level variations are the response of the Earth's oceans to a variety of forcing mechanisms including gravity, surface stress, radiative fluxes, and coastal freshwater discharge. As illustrated in Fig. 1 (adapted from [44]), these variations span a wide range of timescales and the different frequency bands have relevance to a variety of physical processes of interest. For example, capillary waves increase

This article is part of the Topical Collection on Sea Level Projections

David F. Hill

david.hill@oregonstate.edu

1 Civil and Construction Engineering, Oregon State University, 101 Kearney Hall, Corvallis, OR 97331, USA surface roughness and allow for accurate remote sensing of coastal waters [40]. Gravity waves are among the most energetic and are primary drivers of coastal erosion [84]. Lowfrequency, narrow-banded content comes from the semidiurnal and diurnal tidal oscillations due to the sun and moon.

The spatial variability of tidal amplitudes (e.g., Fig. 2) is considerable and is due primarily to bathymetric variations at basin [71], shelf [28], and local [25] scales. The temporal variability of tidal amplitudes is similarly complex, with variations observed at seasonal [59] and decadal (e.g., 18.6-year nodal cycle; [50]) timescales as well as longer-term secular trends (century to millennium, e.g., [35, 69]).

Changes in tidal range, either MN (mean range of tidedifference between mean high water (MHW) and mean low water (MLW)) or GT (great diurnal range - difference between mean higher high water (MHHW) and mean lower low water (MLLW)), inform estimates of relative sea level (RSL) change. MHW is defined as the average of all high water heights over a given time period (tidal epoch), while MHHW is the average of the higher high water height of each day over the epoch. Low tidal datums are defined similarly. A proxy-based change in RSL $\left(\Delta \xi_{\text {rsl }}\right)$ at a given location $(\phi)$ and time $(\tau)$ can be expressed as [75]

$$
\begin{aligned}
\Delta \xi_{\text {rsl }}(\tau, \phi)= & \Delta \xi_{\text {eus }}(\tau)+\Delta \xi_{\text {iso }}(\tau, \phi)+\Delta \xi_{\text {tect }}(\tau, \phi) \\
& +\Delta \xi_{\text {local }}(\tau, \phi)
\end{aligned}
$$

where the terms on the right-hand side represent eustatic, isostatic, tectonic, and local effects. The local effects, in turn, are expressed as

$\Delta \xi_{\text {local }}(\tau, \phi)=\Delta \xi_{\text {tide }}(\tau, \phi)+\Delta \xi_{\text {sed }}(\tau, \phi)$

and include the effects of tidal range change and sediment consolidation. To illustrate the specific role played by 


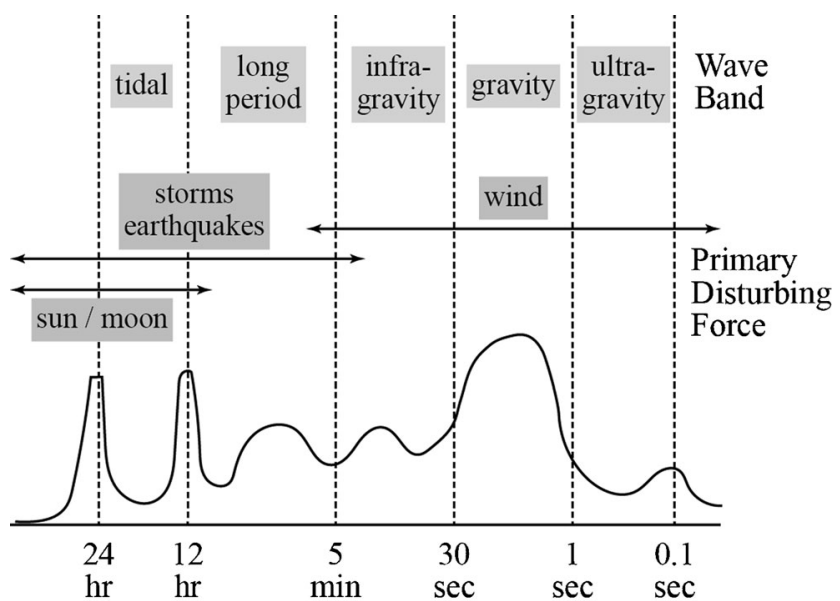

Fig. 1 Conceptual frequency spectrum of ocean surface waves. Adapted from Kinsman [44]

changing tides, note that the establishment of a sea level index point requires information on the geographic location, age, and indicative meaning of a sediment sample [19]. The indicative meaning is the elevation relative to a contemporaneous tide level [66], or reference water level, and this indicative meaning will vary depending upon the biological indicator in the sediment sample. As an example, Horton, Edwards, and Lloyd [41] developed a foraminiferal-based transfer function that provides a standardized water level index (SWLI) as a function of species. The effect of tides and tidal range change comes in through the relationship between the chosen reference water level (e.g., mean high water spring tide (MHWST) for foraminifera) and other tidal datums such as diurnal tide level (DTL - arithmetic mean of MHHW and MLLW) or mean sea level (MSL).

Figure $3 \mathrm{a}$ shows two sediment samples (containing the same species), one at $0 \mathrm{ka}$ (kiloannum; present day) and one

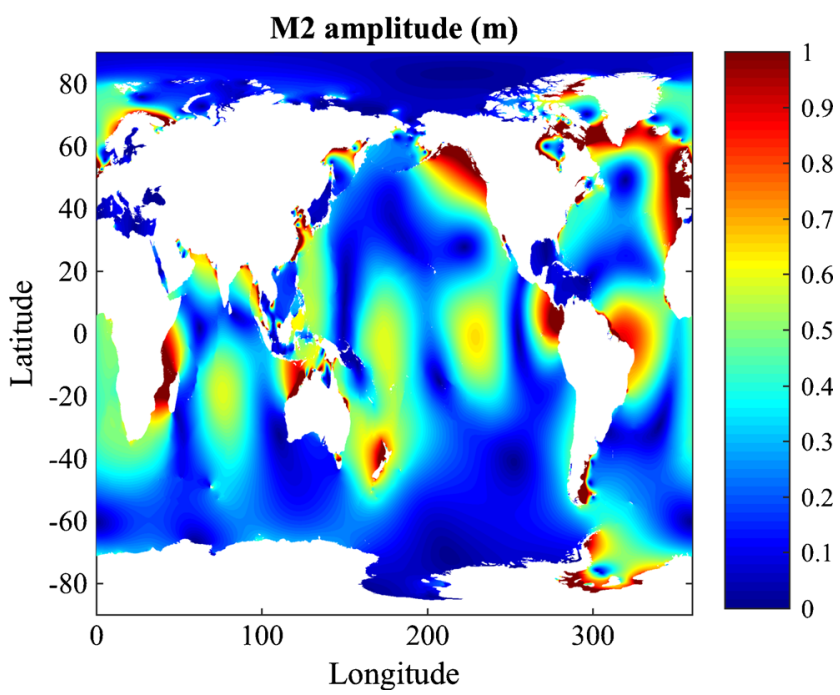

Fig. 2 Distribution of M2 tidal amplitude from the FES2004 tidal model [52] at $5 \mathrm{ka}$. The modern-day ( $0 \mathrm{ka})$ DTL is indicated. If it is assumed that paleotides ( $5 \mathrm{ka}$ ) were the same as modern-day tides, then the RSL change $\left(\mathrm{RSLR}_{5(\mathrm{a})}\right)$ from $5 \mathrm{ka}$ to $0 \mathrm{ka}$ is simply the same as the vertical offset between the two samples. Figure $3 b$ illustrates the effect of changing tidal range. The same sediment sample is shown at its 5-ka location. The tidal datums and relative sea level rise (RSLR) annotated with the 5(a) subscript correspond, as they did in Fig. 3a, to the assumption of constant tidal range. The tidal datums with the 5(b) subscript correspond to the case of larger paleotides. The amplification of the tides at 5 ka produces a larger RSLR than occurred under the assumption of constant tides.

An understanding of tidal range changes is therefore an important element of understanding past and future changes in RSL. It is also important from a coastal flooding point of view as tidal elevations are a contribution to total water levels. This paper begins with a brief review of observational and modeling studies of historic changes in tidal ranges. It then discusses several of the underlying physical mechanisms contributing to these changes. It concludes with some remarks about modeled future changes in tidal range and the effects of these changes on RSL.

\section{Observations of Tidal Range Change}

Direct observations of changes in tidal datums are, of course, limited by data availability. Figure 4 illustrates the periods of record and the latitudinal coverage of global tide gauges, as well as the locations of the gauges themselves. These data are taken from the Permanent Service for Mean Sea Level $[38,68]$ and cover 1445 different gauges (historic and current). Note that PSMSL also distributes a more limited set of data from bottom pressure gauges; those records are not included here. Similarly, data from satellite altimetry are not considered in this review. The average period of record of the tidal gauges is 37 years and the longest is 208 years, and the greatest spatial coverage is in the mid-latitudes of the northern hemisphere. These records provide information on tidal amplitudes and phases through harmonic analysis. Information on tidal datums comes either from direct analysis of the gauge times series or through algorithms (e.g., [56]) that directly convert amplitudes and phases to datums.

Early studies tended to be local, analyzing one or more gauges at or near a particular site. More recent studies have been regional, quasi-global, or global, taking advantage of ongoing efforts to improve the quality of and access to global datasets. Table 1 lists many of the studies of tidal range at the decadal-tocentury timescale permitted by the observational data illustrated in Fig. 4. Note that the studies in Table 1 are limited to those that specifically evaluated changes in tidal amplitudes. There are many other (e.g., [55]) studies that have instead used gauge data to evaluate trends in extreme water levels themselves. 
Fig. 3 Schematics of tidal datums and inferred RSLR. a Constant tidal range between $5 \mathrm{ka}$ and present day $(0 \mathrm{ka})$. b Effect of changing tidal range

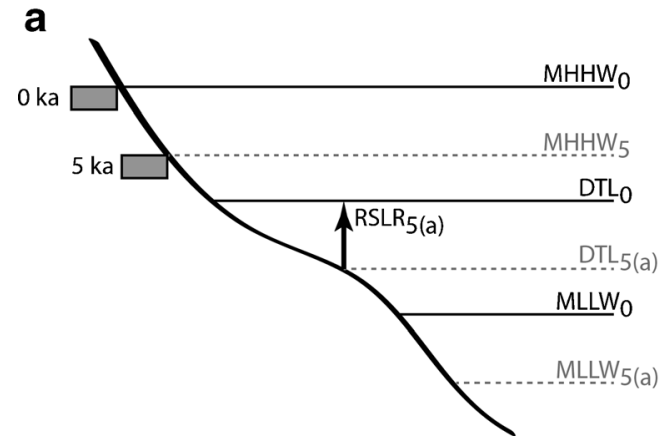

The results of these studies are inconclusive in terms of regional trends and correlations with changes in MSL. Furthermore, changes that were observed at a given location often varied across the tidal constituents. As an example, Ray [69] found that $\mathrm{M}_{2}$ amplitudes have increased in the Gulf of Maine, while Ray [70] found that the $S_{2}$ amplitudes have decreased in that location. The larger-scale studies (e.g., [18, 87]) have in part been carried out in order to find regional trends, but larger-scale patterns have been elusive. Further complicating regional- to global-scale understanding is that local processes and factors often play a role in determining trends. For example, Zaron and Jay [89] note that some of their observed trends in the $\mathrm{M}_{2}$ amplitude were due to changes in station timekeeping and data processing, and others were due to local morphodynamics. Stations where trends were not explained by either of these causes were noted as suggestive of a link between climate (RSL change) and tides.

\section{Modeling Studies of Past Tidal Range Change}

Modeling can fill the spatial gaps between observations (i.e., tide gauges) and the temporal gaps in observational records. An excellent recent review of barotropic tide models is provided by Stammer et al. [77]. Those authors provide a state-ofthe-art comparison of many leading tidal models, including both assimilative (models that ingest observational data) and

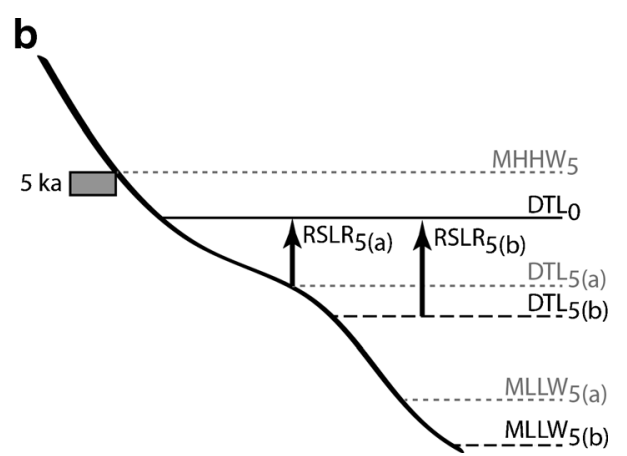

dynamical (models that only rely on physical first principles) models. Most modeling studies of changing tides have focused on millennial timescales rather than the decadal-tocentury timescales of the observational studies. Table 2 summarizes many recent studies, including their geographic scope (local/regional vs. global) and their temporal scope. The included studies go back only as far as $65 \mathrm{ka}$; note that there are additional modeling studies not included here that go back much further, e.g., Hansen [34]. There are many important differences among these studies, including choices and assumptions regarding bathymetry, drag parameterization, and open boundary treatment in the case of non-global studies. Note also that many of the studies in Table 2 have coarse temporal resolution in the sense that they contrast tides at only one point in time to present-day tides. Other studies are more highly resolved with simulations performed at multiple times. One of the most dramatic and consistent results demonstrated by many of these studies is a strong amplification of the $\mathrm{M}_{2}$ tide in the northern Atlantic Ocean at $\sim 9$ ka (Fig. 5).

Paleobathymetries in these studies are obtained in a variety of ways. The simplest model is a spatially uniform change in water depth. This effectively assumes no relative bathymetric change. This model is relatively common in local studies (e.g., [74]), where the length scale of the domain is less than the length scale of glacial isostatic adjustment (GIA) variations but is also sometimes used in global studies (e.g., [57]) where it is less justifiable. Most large-scale studies have instead used spatially variable adjustments to bathymetry informed by GIA
Fig. 4 Latitudinal distribution (a) of tidal gauges and their periods of record. The individual colors cycle through the gauges, with each gauge represented by a length corresponding to its period of record. Location of gauges is shown in (b) a

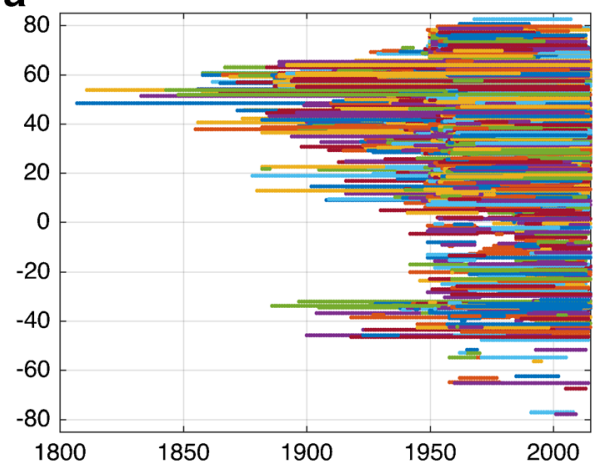

b

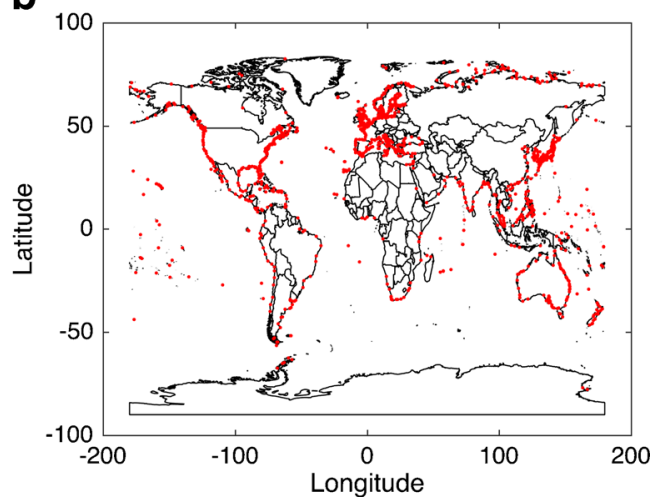


Table 1 Summary of observational studies of changing tidal amplitudes

\begin{tabular}{ll}
\hline Citation & Study scope \\
\hline Local & \\
Bowen [9] & Thames River, England \\
Cartwright [12] & Brest, France \\
Amin [1] & Thames River, England \\
Colosi and Munk [16] & Hawaii, USA \\
Regional & \\
Woodworth, Shaw, and Blackman [88] & British Isles; North Sea \\
Flick, Murray, and Ewing [23] & USA \\
Ray [69] & Gulf of Maine \\
Jay [42] & Eastern Pacific Ocean \\
Ray [70] & Western North Atlantic \\
Müller [58] & North Atlantic \\
Tai and Tanaka [78] & East China Sea \\
Zaron and Jay [89] & Pacific Ocean \\
Devlin et al. [18] & Western Pacific Ocean \\
Global & \\
Woodworth [87] & Quasi global \\
Müller, Arbic, and Mitrovica [60] & Quasi global \\
Mawdsley, Haigh, and Wells [54] & Global \\
\hline
\end{tabular}

models such as ICE-5G [64]. In both local and global studies, it is common to neglect temporal bathymetric variations due to river sedimentation and coastal geomorphological processes.

Table 2 Summary of modeling studies of historic tides

\begin{tabular}{lll}
\hline Citation & Region & Temporal range \\
\hline Local/regional & & \\
Scott and Greenberg [74] & Bay of Fundy & $0-7$ ka \\
Austin [7] & European shelf & Holocene \\
Hinton [36] & UK & Holocene \\
Gehrels et al. [27] & Bay of Fundy & $0-7$ ka \\
Tojo, Ohno, and Fujiwara [80] & Osaka Bay, Japan & Late Pleistocene \\
Uehara [81] & Yellow/East China Seas & Holocene \\
Shennan et al. [76] & UK & Holocene \\
Uehara et al. [82] & European shelf & 0 -last glacial \\
& & maximum (LGM) \\
Leorri et al. [47] & Delaware Bay, USA & $0-4$ ka \\
Hill et al. [35] & Western North Atlantic & Holocene \\
Hall et al. [33] & Delaware Bay, USA & $0-7$ ka \\
Global & & \\
Thomas and Sündermann [79] & Global & 0 ka-LGM \\
Egbert, Ray, and Bills [22] & Global & 0 ka-LGM \\
Montenegro et al. [57] & Global & 0 ka-LGM \\
Arbic et al. [4] & Global & $0-65$ ka \\
Griffiths and Peltier [32] & Global & 0 ka-LGM \\
Green et al. [31] & Global & 0 ka-LGM \\
\hline
\end{tabular}

While this assumption is valid for large-scale studies (where those processes may be subgrid scale), it is less tenable for local (bay/estuary scale) studies where sediment infill may be an important control on tidal hydrodynamics.

Regarding drag, most models account for a turbulent bottom boundary layer through the use of a classical drag law [53]. Egbert and Ray [21] suggest that generation of internal tides (see [26]), in a globally averaged sense, is on the same of order of magnitude of bottom friction, in terms of a dissipation mechanism for surface tides. Green and Nycander [30] discuss several ways for incorporating internal tidal drag into global tidal models. It is difficult, however, to implement internal tidal drag parameterizations into paleotidal simulations since the stratification of the ocean is not well constrained at those earlier times. This is particularly consequential since, at those earlier times, the continental shelves are smaller in extent, which increases the dominance of (poorly constrained) internal tidal drag in the overall dissipation. Griffiths and Peltier [32] illustrate a path forward in their simulations, by using coupled atmosphereocean models to estimate the buoyancy frequency of the water column, from which the drag is parameterized.

Finally, local/regional tidal simulations necessarily have one or more open boundaries, at which the tides must be prescribed. Many studies assume that the paleotides at these open boundaries are the same as present day. In some cases, this is assumed for convenience or lack of knowledge of the paleotides. In other cases (e.g., [33]), the assumption is justified through global tidal models that demonstrate only marginal changes in tides at these boundaries. In the case of local/regional (e.g., [35, 82]) studies that span a large enough time range for significant tidal changes to occur at the open boundaries, nested modeling approaches must be used in order to correctly specify the open boundary tides.

\section{Physical Mechanisms of Tidal Range Change}

Tidal amplitudes at a coastal location are controlled both by farfield and local effects. As Fig. 5 demonstrated, tidal amplitudes in the western North Atlantic are relatively spatially coherent and are determined largely by the geometry of the basin. In this way, the tides in a local estuary on the east coast of the USA are controlled by the Atlantic. However, there is also considerable variability in tidal amplitudes along that coast and this variability is controlled by the particular bathymetry (open coast vs. inner estuary vs. upriver, etc.) of each gauging location. Therefore, changes in tidal range can originate from changes to larger basin-scale characteristics or from changes to local characteristics.

Beginning with local effects, much is known about the propagation of tidal waves in estuaries and rivers [37, 73]. Variations in depth and width interact with frictional effects and river flow to produce a complex structure of tidal 
Fig. 5 Ratios of $\mathrm{M}_{2}$ amplitudes at given time to those of present day (figure from [35])
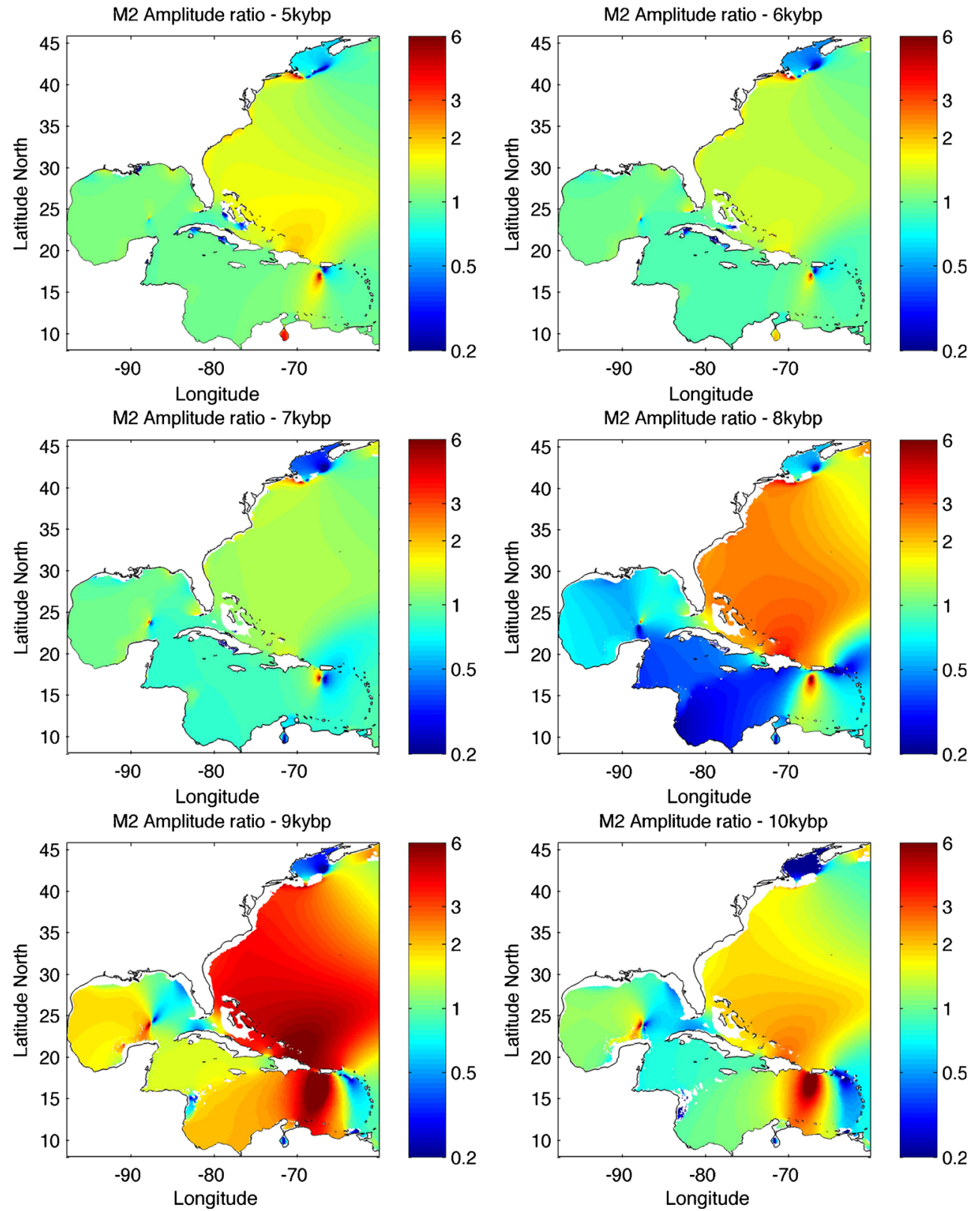

amplitude along the length of a tidal river. As noted by Chernetsky, Schuttelaars, and Talke [14]; Cai et al. [10]; and Cai and Savenije [11], deepening of a channel can lead to significant increases in tidal range. The increases are not monotonic, however; beyond a critical depth, it is possible for the tidal amplitudes to reduce as the progressive tidal wave transitions to a standing wave. Local anthropogenic effects (reclamation, shoreline changes, etc.) have also been shown to impact not only tidal currents (e.g., [46]), but also tidal amplitudes [43, 63].

At a larger scale, the effect of continental shelf width (and depth) on tidal amplitudes has been considered (e.g., [2, 3, 5, $15,17])$ ). For a simple example, the study by Clarke and
Battisti [15] suggests (see their Fig. 3) that shelf resonance occurs when the shelf scale

$\frac{g \alpha}{\omega^{2}-f^{2}}$

is approximately equal to the shelf width. In the above, $g$ is the gravity, $\alpha$ is the shelf slope, $\omega$ is the tidal frequency, and $f$ is the Coriolis parameter. Figure 6 demonstrates the considerable loss of continental shelf width that accompanied the Holocene ( $\sim 10 \mathrm{ka})$. While this quarter wave resonance is an important mechanism controlling shelf tides, it is clear that substantial changes to the resonance characteristics will require substantial changes to MSL. 
Fig. 6 Present-day (a) bathymetry/topography for the Western North Atlantic Ocean. Bathy/topo with a 100-m reduction in MSL is shown at (b)
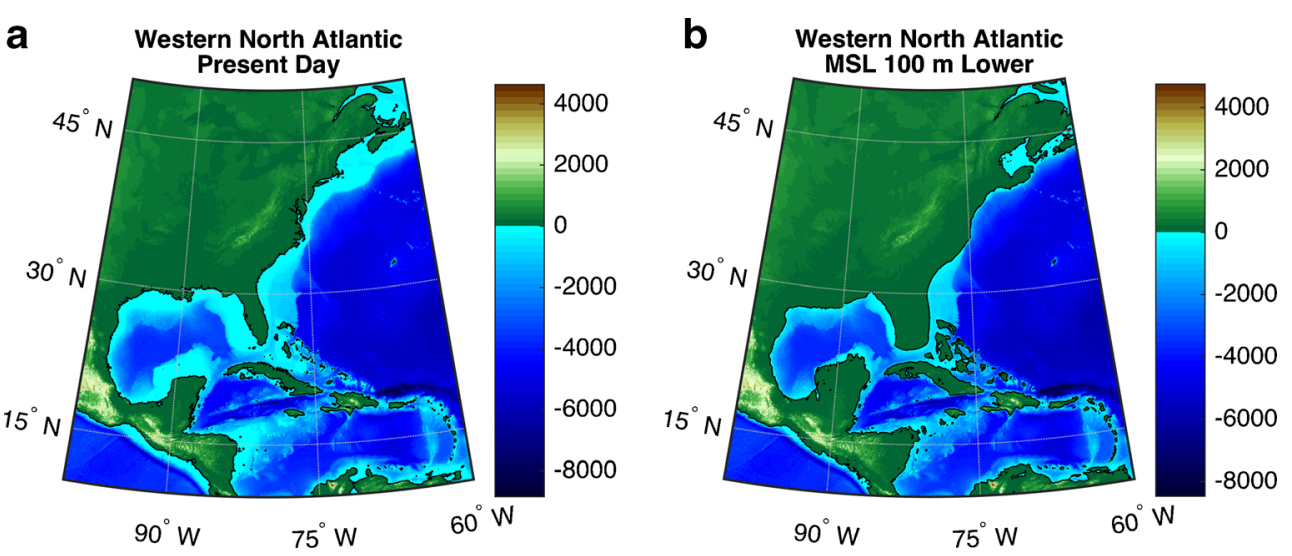

At the largest scale, basin-scale tides are set by basin geometry (proximity of resonant modes to tidal frequencies; see, e.g., [67]) and dissipation. Many studies have identified key global sites such as the Hudson Bay/Strait system (e.g., [20, 48]), the Gulf of Maine, and the Patagonian shelf [3] as the main locations of dissipation of the $\mathrm{M}_{2}$ tide. Removal of these sites (such as in the case of the lowered sea level in Fig. 6b) has been shown to lead to large increases in that tide. As with changes to shelf resonance, this mechanism for tidal range change requires large perturbations to MSL. Finally, as noted earlier, baroclinic motions are an important sink for barotropic tidal energy. Therefore, changes in ocean stratification (which controls the baroclinic motions) have the potential to lead to changes in the surface tides [42], although this is a relatively unexplored and, therefore, active research area. Wetzel et al. [86] investigate this by developing a two-layer analytical tidal model which serves as a framework for quantifying the sensitivity of surface tides to changes in stratification, and the simulations by Müller et al. [59] show that seasonal variations in the mixed layer depth affect the $\mathrm{M}_{2}$ tide amplitude.

\section{Modeling Studies of Climate Change and Future Tidal Range}

It was noted previously that most modeling studies of changing tides were focused on paleotides and on millennial timescales. In recent years, there has been an increasing interest in the future of tides. This interest is largely driven by projected increases in sea level and concerns about coastal flooding. As just one example, Kopp et al. [45] use probabilistic methods to provide century-scale projections of RSL rise at a global network of tide gauge locations. An increasing tidal range will lead to greater flooding than predicted by changes in sea level alone. It was further noted earlier that changes in tides can originate from global drivers, i.e., changes in resonance characteristics of the major ocean basins, or from local drivers, i.e., changes in sea level, sedimentation, anthropogenic influences, and so on.

Table 3 summarizes many recent studies of changing tidal range under future scenarios, including their geographic scope and methods (mode of change). All of these studies are local

Table 3 Summary of modeling studies of future tides

\begin{tabular}{|c|c|c|}
\hline Citation & Region & Methods \\
\hline French $[24]$ & Eastern England & $\begin{array}{l}\text { +0.3 m SLR; managed retreat scenarios of defense structures; } \\
\text { sedimentation effects }\end{array}$ \\
\hline Greenberg et al. [29] & Bay of Fundy & Spatially variable SLR; simulations for 2055, 2085, 2100 \\
\hline Pickering et al. [65] & European Shelf & $+2,+10 \mathrm{~m} \mathrm{SLR}$ \\
\hline Ward, Green, and Pelling [85] & European Shelf & $-2,-1, \ldots,+5 \mathrm{~m} \mathrm{SLR}$ \\
\hline Pelling, Uehara, and Green [63] & Bohai Sea, China & $+1,+2,+3 \mathrm{~m}$ SLR; land subsidence and reclamation effects \\
\hline Valentim et al. [83] & Portugal & $+0.42 \mathrm{~m} \mathrm{SLR}$ \\
\hline Hall et al. [33] & Delaware Bay, USA & $\begin{array}{l}\text { Spatially variable GIA adjustment plus eustatic SLR } \\
\text { corresponding to }+0.1,+0.3 \mathrm{ka}\end{array}$ \\
\hline Rosier et al. [72] & Antarctic & Ice shelf thinning and retreat \\
\hline Luz Clara et al. [51] & Patagonia Shelf & $+1,+2,+10 \mathrm{~m} \mathrm{SLR}$ \\
\hline Holleman and Stacey [39] & San Francisco Bay, USA & $+0.6,+1 \mathrm{~m} \mathrm{SLR}$ \\
\hline Arns et al. [6] & North Sea & $+0.54 \mathrm{~m} \mathrm{SLR}$ \\
\hline Passeri et al. [62] & Northern Gulf of Mexico & $\begin{array}{l}\text { Eight SLR scenarios from }+0.1 \text { to }+2.0 \mathrm{~m} \text {. Probabilistic } \\
\text { model for shoreline and dune height changes }\end{array}$ \\
\hline
\end{tabular}


to regional in scope, which highlights the fact that future changes in tidal range, under realistic century-scale (a few meters) sea level rise (SLR) scenarios, will be controlled by local effects and conditions. Put another way, ocean basinscale processes will not be noticeably affected by depth increases of this amount. The studies in Table 3 are focused on, or explicitly give results for, tidal amplitude changes. It should be noted that there are many more studies (e.g., [8, 13, 49]) that consider a more holistic approach to changing extreme water elevations, of which tides are a component. Studies that do not explicitly provide information on the changes to tidal amplitudes are not included in Table 3.

As with the modeling studies of past tides, there are important decisions to be made with regard to modeling strategy and the implementation of future conditions. Generally speaking, studies have modeled future conditions with a simple spatially constant increase (equal to the assumed SLR) in water depth, though there are exceptions $[30,33]$. There is also variability in the treatment of inundation of formerly dry land as sea level rises. Some studies use a vertical boundary at the present-day coastline, which precludes inundation, while others use a combined bathy-topo model grid and allow for the landward migration of the coastline with SLR. One place of unanimity is that future open boundary tides are assumed to be equal to present-day tides, which is a well-justified assumption provided that the open boundary is in sufficiently deep water.

Typically, sedimentation effects and coastline change are ignored. French [24] is a noteworthy counter-example since that study modified the bathymetric change based both on SLR projections and on historic sedimentation rates. Similarly, Passeri et al. [62] use probabilistic methods to evolve the coastline and dune heights to accompany their adopted SLR scenarios. While many studies have reported modest increases in tidal amplitudes $\left(\mathrm{M}_{2}\right.$ is the most commonly studied constituent), it is difficult to generalize results due to the different characteristics of the various study sites.

\section{Concluding Remarks}

There is ample evidence that tidal amplitudes in coastal waters are not constant in time. These changes are not driven by changes in forcing but rather by changes in geometry (which alters resonance, wave speed, and other quantities) and in surface characteristics (i.e., changes in roughness which can alter damping). Tides play a major role in coastal total water levels, so constraining the range of changes that can be expected on a decadal-to-century timescale is valuable for hazard planning. Constraining these changes is also of value in terms of more accurately determining rates of RSL change at coastal locations.
Studies to date of changing tidal range have provided valuable insight into the magnitudes of the observed and likely future changes and into the physical mechanisms that contribute to these changes. Out of necessity, many of these studies have used simplified approaches, especially in terms of how to determine the geometry and boundary roughness of the model domain for paleo and future simulations. Because of this uncertainty, it is possibly most useful to think of existing studies of future tidal conditions as sensitivity experiments rather than predictive studies. Also, given the relatively modest (meter scale) increases in MSL expected in the coming centuries, tidal changes will likely be driven by local rather than farfield changes.

With increasing emphasis on the future of coastal waters and sustainability of coastal communities and ecosystems, it is likely that modeling efforts will become increasingly sophisticated in their ability to develop accurate future model grids (sedimentation, evolving land cover, and vegetation; see Passeri et al. [61] for a review). This continual refinement of models, their grids, and their boundary conditions will lead to increasingly accurate estimates of the future behavior of tides and local sea level changes.

\section{References}

1. Amin M. On perturbations of harmonic constants in the Thames estuary. Geophys J Int. 1983;73(3):587-603. doi:10.1111/j.1365246X.1983.tb03334.x.

2. Arbic BA, Garrett C. A coupled oscillator model of shelf and ocean tides. Cont Shelf Res. 2010;30:564-74.

3. Arbic BK, Karsten RH, Garrett C. On tidal resonance in the Global Ocean and the back-effect of coastal tides upon open-ocean tides. Atmosphere-Ocean. 2009;47(4):239-66.

4. Arbic BK, Mitrovica JX, MacAyeal DR, Milne GA. On the factors behind large Labrador Sea tides during the last glacial cycle and the potential implications for Heinrich events. Paleoceanography. 2008;23:1-14.

5. Arbic BK, St-Laurent P, Sutherland G, Garrett C. On the resonance and influence of the tides in Ungava Bay and Hudson Strait. Geophys Res Lett. 2007;34(L17606). doi:10.1029/2007GL03085.

6. Arns A, Wahl T, Dangendorf S, Jensen J. The impact of sea level rise on storm surge water levels in the northern part of the German Bight. Coast Eng. 2015;96:118-31. doi:10.1016/j. coastaleng.2014.12.002.

7. Austin RM. Modelling Holocene tides on the NW European continental shelf. Terra Nova. 1991;3(3):276-88. doi:10.1111/j.13653121.1991.tb00145.x.

8. Bilskie MV, Hagen SC, Medeiros SC, Passeri DL. Dynamics of sea level rise and coastal flooding on a changing landscape. Geophys Res Lett. 2014;41(3):927-34. doi:10.1002 /2013GL058759.

9. Bowen AJ. The tidal régime of the River Thames; long-term trends and their possible causes. Philos Trans R Soc Lond Proc R Soc 
Lond A Math Phys Sci. 1972;272(1221):187-99. doi:10.2307 174029 .

10. Cai H, Savenije HH, Yang Q, Ou S, Lei Y. Influence of river discharge and dredging on tidal wave propagation: Modaomen estuary case. J Hydraul Eng. 2012;138(10):885-96.

11. Cai H, Hubert HGS. Asymptotic behavior of tidal damping in alluvial estuaries. J Geophys Res Oceans. 2013;118(11):6107-22. doi:10.1002/2013JC008772.

12. Cartwright DE. Secular changes in the oceanic tide at Brest. Geophys J R Astron Soc. 1972;30:433-49.

13. Cheng TK, Hill DF, Beamer J, García-Medina G. Climate change impacts on wave and surge processes in a Pacific Northwest (USA) estuary. J. Geophys. Res. Oceans. 2015;120(1):182-200. doi:10.1002/2014JC010268.

14. Chernetsky AS, HM S, SA T. The effect of tidal asymmetry and temporal settling lag on sediment trapping in tidal estuaries. Ocean Dyn. 2010;60(5):1219-41. doi:10.1007/s10236-010-0329-8.

15. Clarke AJ, David SB. The effect of continental shelves on tides. Deep Sea Res Part A. 1981;28(7):665-82. doi:10.1016/0198-0149 (81)90128-X.

16. Colosi JA, Munk W. Tales of the venerable Honolulu tide gauge. J Phys Oceanogr. 2006;36(6):967-96. doi:10.1175/JPO2876.1.

17. Cram JM. The influence of continental shelf width on tidal range: paleoceanographic implications. Afr J Geol. 1979;87(4):441-7.

18. Devlin AT, Jay DA, Talke SA, Zaron E. Can tidal perturbations associated with sea level variations in the western Pacific Ocean be used to understand future effects of tidal evolution? Ocean Dyn. 2014;64(8):1093-120. doi:10.1007/s10236-014-0741-6.

19. Edwards RJ, Horton BP. Developing detailed records of relative sea-level change using a foraminiferal transfer function: an example from North Norfolk, UK. Philos Trans R Soc A Math Phys Eng Sci. 2006;364(1841):973-91. doi:10.1098/rsta.2006.1749.

20. Egbert GD, Ray RD. Significant dissipation of tidal energy in the deep ocean inferred from satellite altimeter data. Nature. 2000;405(6788):775-8. doi:10.1038/35015531.

21. Egbert GD, Ray RD. Semi-diurnal and diurnal tidal dissipation from TOPEX/Poseidon altimetry. Geophys Res Lett. 2003;30: 1907.

22. Egbert GD, Ray RD, Bills BG. Numerical modeling of the global semidiurnal tide in the present day and in the last glacial maximum. J Geophys Res. 2004;109(C3):1-15.

23. Flick R, Murray J, Ewing L. Trends in United States tidal datum statistics and tide range. J Waterw Port Coast Ocean Eng. 2003;129(4):155-64. doi:10.1061/(ASCE)0733-950X(2003)129 $: 4(155)$.

24. French JR. Hydrodynamic modelling of estuarine flood defence realignment as an adaptive management response to sea-level rise. J Coast Res. 2008;24(2B):1-12.

25. Garrett C. Tidal resonance in the Bay of Fundy and Gulf of Maine. Nature. 1972;238:441-3.

26. Garrett C, Kunze E. Internal tide generation in the deep ocean. Annu Rev Fluid Mech. 2007;39(1):57-87. doi:10.1146/annurev. fluid.39.050905.110227.

27. Gehrels WR, Belknap DF, Pearce BR, Gong B. Modeling the contribution of M2 tidal amplification to the Holocene rise of mean high water in the Gulf of Maine and the Bay of Fundy. Mar Geol. 1995;124:71-85.

28. Glorioso PD and Flather RA. 1997. The Patagonian Shelf tides. Progress in Oceanography, Tidal science in honour of David E. Cartwright, 40 (1-4): 263-83. doi:10.1016/S00796611(98)00004-4.

29. DA G, Blanchard W, Smith B, Barrow E. Climate change, mean sea level and high tides in the Bay of Fundy. Atmosphere-Ocean. 2012;50(3):261-76. doi:10.1080/07055900.2012.668670.
30. Green JAM, Nycander J. A comparison of tidal conversion parameterizations for tidal models. J Phys Oceanogr. 2012;43(1):104-19. doi:10.1175/JPO-D-12-023.1.

31. Green JAM, Green CL, Bigg GR, Rippeth TP, Scourse JD, Uehara $\mathrm{K}$. Tidal mixing and the strength of the meridional overturning circulation from the last glacial maximum. Geophys Res Lett. 2009;36:L15603.

32. Griffiths SD, Peltier WR. Modeling of polar ocean tides at the last glacial maximum: amplification, sensitivity, and climatological implications. J Clim. 2009;22:2905-224.

33. Hall GF, Hill DF, Horton BP, Engelhart SE, Peltier WR. A highresolution study of tides in the Delaware Bay: past conditions and future scenarios. Geophys Res Lett. 2013;40(2):338-42. doi:10.1029/2012GL054675.

34. Hansen KS. Secular effects of oceanic tidal dissipation on the Moon's orbit and the Earth's rotation. Rev Geophys. 1982;20(3): 457-80. doi:10.1029/RG020i003p00457.

35. Hill DF, Griffiths SD, Peltier WR, Horton BP, Tornqvist TE. Highresolution numerical modeling of tides in the western Atlantic, Gulf of Mexico, and Caribbean Sea during the Holocene. J Geophys Res. 2011;116:C10014.

36. Hinton AC. Paleotidal changes within the area of the wash during the Holocene. Proc Geol Assoc. 1992;103:259-72.

37. Hoitink AJF, Jay DA. Tidal river dynamics: implications for deltas. Rev Geophys. 2016;54(1):2015RG000507. doi:10.1002/2015 RG000507.

38. Holgate SJ, A Matthews, PL. Woodworth, LJ. Rickards, ME. Tamisiea, E Bradshaw, PR. Foden, KM. Gordon, SJ Evrejeva, and J Pugh. 2012. New data systems and products at the permanent service for mean sea level. Journal of Coastal Research, December, 493-504. doi:10.2112/JCOASTRES-D-12-00175.1.

39. Holleman RC, Stacey MT. Coupling of sea level rise tidal amplification, and inundation. J Phys Oceanogr. 2014;44(5):1439-55. doi:10.1175/JPO-D-13-0214.1.

40. Holman R, Haller MC. Remote sensing of the nearshore. Ann Rev Mar Sci. 2013;5(1):95-113. doi:10.1146/annurev-marine-121211172408.

41. Horton BP, Edwards RJ, Lloyd JM. A foraminiferal-based transfer function: implications for sea-level studies. Can J For Res. 1999;29(2):117-29. doi:10.2113/gsjfr.29.2.117.

42. Jay DA. Evolution of tidal amplitudes in the eastern Pacific Ocean. Geophys Res Lett. 2009;36(4):L04603. doi:10.1029/2008 GL036185.

43. Kang SK, Jung KT, Kim EJ, So JK, Park JJ. Tidal regime change due to the large scale of reclamation in the west coast of the Korean peninsula in the yellow and East China seas. J Coast Res. 2013: 254-9. doi:10.2112/SI65-044.1.

44. Kinsman, Blair. 1965. Wind waves: their generation and propagation on the ocean surface. Prentice Hall.

45. Kopp, Robert E., Radley M. Horton, Christopher M. Little, Jerry X. Mitrovica, Michael Oppenheimer, D. J. Rasmussen, Benjamin H. Strauss, and Claudia Tebaldi. 2014. Probabilistic 21st and twentysecond century sea-level projections at a global network of tidegauge sites. Earth 's Future 2 (8): 2014EF000239. doi:10.1002/ 2014EF000239.

46. Kuang Cp, Huang J, Lee JHW, Gu J. Impact of large-scale reclamation on hydrodynamics and flushing in Victoria harbour, Hong Kong. J Coast Res. 2013:128-43. doi:10.2112/JCOASTRES-D-1100153.1.

47. Leorri E, Mulligan R, Mallinson D, Cearreta A. Sea-level rise and local tidal range changes in coastal embayments: an added complexity in developing reliable sea-level index points. J Integ Coastal Zone Manag. 2011;241(3-4):307-14.

48. LeProvost $\mathrm{C}$, Lyard $\mathrm{F}$. Energetics of the $\mathrm{M}_{2}$ barotropic ocean tides: an estimate of bottom friction dissipation from a hydrodynamic model. Prog Oceanogr. 1997;40:37-52. 
49. Lin N, Emanuel K, Oppenheimer M, Vanmarcke E. Physically based assessment of hurricane surge threat under climate change. Nat Clim Chang. 2012;2(6):462-7. doi:10.1038/nclimate1389.

50. Loder JW, Garrett C. The 18.6-year cycle of sea surface temperature in shallow seas due to variations in tidal mixing. J. Geophys. Res. Oceans. 1978;83(C4):1967-70. doi:10.1029/JC083iC04p01967.

51. Moira Luz Clara, Claudia G. Simionato, Enrique D'Onofrio, and Diego Moreira. 2014. Future sea level rise and changes on tides in the Patagonian continental shelf. Journal of Coastal Research, September, 519-35. doi:10.2112/JCOASTRES-D-13-00127.1.

52. Lyard F, Lefevre F, Letellier T, Francis O. Modelling the Global Ocean tides: modern insights from FES2004. Ocean Dyn. 2006;56(5-6):394-415. doi:10.1007/s10236-006-0086-x.

53. Marchuk, G. I., and B. A. Kagan. 1989. Bottom boundary layer in tidal flow: theoretical models. In Dynamics of ocean tides, 266308. Oceanographic Sciences Library 3. Springer Netherlands. http://link.springer.com/chapter/10.1007/978-94-009-2571-7_10.

54. Mawdsley, Robert J., Ivan D. Haigh, and Neil C. Wells. 2015. Global secular changes in different tidal high water, low water and range levels. Earth's Future 3 (2): 2014EF000282. doi: 10.1002/2014EF000282.

55. Menéndez M, Woodworth PL. Changes in extreme high water levels based on a quasi-global tide-gauge data set. J. Geophys. Res. Oceans. 2010;115(C10):C10011. doi:10.1029/2009 JC005997.

56. Mofjeld HO, Venturato AJ, Gonzales FI, Titov VV, Newman JC. The harmonic constant datum method: options for overcoming datum discontinuities at mixed-diurnal tidal transitions. J Atmos Ocean Technol. 2004;21:95-104.

57. Montenegro A, Eby M, Weaver AJ, Jayne SR. Response of a climate model to tidal mixing parameterization under present day and last glacial maximum conditions. Ocean Model. 2007;19:125-37.

58. Müller M. Rapid change in semi-diurnal tides in the North Atlantic since 1980. Geophys Res Lett. 2011;38(11):L11602. doi:10.1029 /2011GL047312.

59. Müller M, Cherniawsky JY, Foreman MGG, von Storch J-S. Seasonal variation of the M2 tide. Ocean Dyn. 2014;64(2):15977. doi:10.1007/s10236-013-0679-0.

60. Müller M, Arbic BK, Mitrovica JX. Secular trends in ocean tides: observations and model results. J. Geophys. Res. Oceans. 2011;116(C5):C05013. doi:10.1029/2010JC006387.

61. Passeri, Davina L., Scott C. Hagen, Stephen C. Medeiros, Matthew V. Bilskie, Karim Alizad, Dingbao Wang. 2015. The dynamic effects of sea level rise on low-gradient coastal landscapes: a review. Earth 's Future3 (6): 2015 EF000298. doi:10.1002/ 2015 EF000298.

62. Passeri, Davina L, Scott C Hagen, Nathaniel G Plant, Matthew V Bilskie, Stephen C Medeiros, Karim Alizad. 2016. Tidal hydrodynamics under future sea level rise and coastal morphology in the Northern Gulf of Mexico. Earth's Future, March, 2015EF000332. doi:10.1002/2015EF000332.

63. Pelling HE, Uehara K, Green J a M. The impact of rapid coastline changes and sea level rise on the tides in the Bohai Sea, China. J. Geophys. Res. Oceans. 2013;118(7):3462-72. doi:10.1002 jigrc.20258.

64. Peltier WR. Global glacial isostasy and the surface of the ice-age earth: the ICE-5G (VM2) model and GRACE. Annu Rev Earth Planet Sci. 2004;32:111-49.

65. Pickering MD, Wells NC, Horsburgh KJ, Green JAM. The impact of future sea-level rise on the European shelf tides. Cont Shelf Res. 2012;35:1-15. doi:10.1016/j.csr.2011.11.011.

66. Plassche van de O. 1986. Sea-level research: a manual for the collection and evaluation of data. In, edited by O. van de Plassche, 126. Norwich: Geobooks.
67. Platzman GW. Normal modes of the World Ocean. Part III: a procedure for tidal synthesis. J Phys Oceanogr. 1984;14(10):1521-31. doi:10.1175/1520-0485(1984)014<1521:NMOTWO>2.0.CO;2.

68. PSMSL. 2016. Tide gauge data. April 11. http://www.psmsl. org/data/obtaining/.

69. Ray RD. Secular changes of the M tide in the Gulf of Maine. Cont Shelf Res. 2006;26(3):422-7. doi:10.1016/j.csr.2005.12.005.

70. Ray RD. Secular changes in the solar semidiurnal tide of the western North Atlantic Ocean. Geophys Res Lett. 2009;36(19):L19601. doi:10.1029/2009GL040217.

71. Roos PC, Velema JJ, Hulscher SJMH, Stolk A. An idealized model of tidal dynamics in the North Sea: resonance properties and response to large-scale changes. Ocean Dyn. 2011;61(12):2019-35. doi:10.1007/s10236-011-0456-X.

72. Rosier SHR, Green J a M, Scourse JD, Winkelmann R. Modeling Antarctic tides in response to ice shelf thinning and retreat. J. Geophys. Res. Oceans. 2014;119(1):87-97. doi:10.1002/2013 JC009240.

73. Savenije, Hubert H. G. 2005. 3-tidal dynamics. In Salinity and tides in alluvial estuaries, 69-107. Amsterdam: Elsevier Science Ltd. http://www.sciencedirect.com/science/article/ pii/B9780444521071500046.

74. Scott DB, Greenberg DA. Relative sea-level rise and tidal development in the Fundy tidal system. Can J Earth Sci. 1983;20:1554-64.

75. Shennan I, Horton B. Holocene land- and sea-level changes in Great Britain. J Quat Sci. 2002;17(5-6):511-26. doi:10.1002 /jqs. 710 .

76. Shennan, I., T. Coulthard, R. Flather, B. P. Horton, M. Macklin, J. Rees, M. R. Wright. 2003. Integration of shelf evolution and river basin models to simulate Holocene sediment dynamics of the Humber Estuary during periods of sea-level change and variations in catchment sediment supply. Sci Total Environ 314-316: 737-54.

77. Stammer D, Ray RD, Andersen OB, Arbic BK, Bosch W, Carrère L, Cheng Y, et al. Accuracy assessment of global barotropic ocean tide models. Rev Geophys. 2014;52(3):243-82. doi:10.1002/2014 RG000450.

78. Tai, Akira, and Kaori Tanaka. 2014. Secular changes in the tidal amplitude and influence of sea-level rise in the East China Sea. J Disas Res 9 (1): 48-54. doi:10.20965/jdr.2014.p0048

79. Thomas M, Sündermann J. Tides and tidal torques of the World Ocean since the last glacial maximum. J Geophys Res. 1999;104(C2):3159-83.

80. Tojo B, Ohno T, Fujiwara T. Late Pleistocene changes of tidal amplitude and phase in Osaka Bay, Japan, reconstructed from fossil records and numerical model calculations. Mar Geol. 1999;157(34):241-8. doi:10.1016/S0025-3227(98)00157-1.

81. Uehara K. Tidal changes in the Yellow/East China Sea caused by the rapid sea-level rise during the Holocene. Sci China Ser B Chem. 2001;44(1):126-34. doi:10.1007/BF02884818.

82. Uehara K, Scourse JD, Horsburgh KJ, Lambeck K, Purcell AP. Tidal evolution of the northwest European shelf seas from the last glacial maximum to the present. J Geophys Res. 2006;111(C9):115 .

83. Valentim, Juliana Marques, Leandro Vaz, Nuno Vaz, Helena Silva, Bernardo Duarte, Isabel Caçador, and João Miguel Dias. 2013. Sea level rise impact in residual circulation in Tagus Estuary and Ria de Aveiro Lagoon. Journal of Coastal Research, January, 1981-86. doi:10.2112/SI65-335.1.

84. van Rijn, L. C. 2011. Coastal erosion and control. Ocean \& Coastal Manag Concepts and Scie Coastal Erosion Manag (Conscience), 54 (12): 867-87. doi:10.1016/j.ocecoaman.2011.05.004.

85. Ward SL, Mattias Green JA, Pelling HE. Tides, sea-level rise and tidal power extraction on the European shelf. Ocean Dyn. 2012;62(8):1153-67. doi:10.1007/s10236-012-0552-6.

86. Wetzel, Alfredo N., Brian K. Arbic, Ivana Cerovecki, Myrl C. Hendershott, Richard H. Karsten, Peter D. Miller, and Joseph F. 
Molinari. 2013. On stratification, barotropic tides, and secular changes in surface tidal elevations: two-layer analytical model. arXiv:1311.6349 [physics], November. http://arxiv. org/abs/1311.6349.

87. Woodworth PL. A survey of recent changes in the main components of the ocean tide. Cont Shelf Res. 2010;30(15):1680-91. doi:10.1016/j.csr.2010.07.002.
88. Woodworth PL, Shaw SM, Blackman DL. Secular trends in mean tidal range around the British isles and along the adjacent European coastline. Geophys J Int. 1991;104(3):593-609. doi:10.1111 /j.1365-246X.1991.tb05704.x.

89. Zaron ED, Jay DA. An analysis of secular change in tides at openocean sites in the Pacific. J Phys Oceanogr. 2014;44(7):1704-26. doi:10.1175/JPO-D-13-0266.1. 